\title{
Residue depletion of ivermectin in broiler poultry
}

\author{
Nora Mestorino ${ }^{a}$, Daniel Buldain ${ }^{\mathrm{a}, \mathrm{b}}$, Andrea Buchamer ${ }^{\mathrm{a}}$, Lihuel Gortari ${ }^{\mathrm{a}}$, Martín Daniele ${ }^{\mathrm{a}}$ \\ and María Laura Marchetti ${ }^{a}$ \\ aLaboratory of Pharmacological and Toxicological Studies (LEFyT), Faculty of Veterinary Science, Universidad Nacional de La Plata, La Plata, \\ Argentina; ${ }^{b}$ Consejo Nacional delnvestigaciones Científicas y Técnicas (CINICET), La Plata, Argentina
}

\begin{abstract}
Helminth infections are widespread in the poultry industry. There is evidence of extra-label use of some drugs, such as ivermectin (IVM), in broiler poultry. Pharmacokinetic and residual studies of IVM in poultry, however, are rather scarce. Our aim was to determine time restrictions for broiler chickens fed with balanced feed mixed with IVM for 21 days, and thus achieve acceptable residual levels for consumption as established by the European Union. Sixty 1-day-old chicks were fed with food supplemented with IVM at $5 \mathrm{mg} \mathrm{kg}^{-1}$ feed for 21 days. Groups of six treated animals were sacrificed at $0,1,2,4,8,10,15,20$ and 28 days after treatment. Liver, skin/fat, kidney and muscle samples were obtained. IVM were determined by liquid chromatography with fluorescence detection after automatic solid-phase extraction with SPE $\mathrm{C}_{18}$ cartridges. The highest concentrations were measured in the liver, which is logical given that IVM is a drug that undergoes extensive hepatic metabolism. The optimal withdrawal time for edible tissues of these animals to stay within the permitted residual levels were: 12 days for liver, 8 days for skin/fat, 0 days for muscle and 10 days for kidney.
\end{abstract}

\section{ARTICLE HISTORY}

Received 8 September 2016 Accepted 23 December 2016

\section{KEYWORDS}

Endectocide; ivermectin; chicken; residues; withdrawal time

\section{Introduction}

Domestic birds are frequently affected by internal parasites (Capillaria spp., Ascardia spp., Heterakis gallinarum, Syngamus trachea) and external parasites (Dermanyssus gallinae, scabies mites Cnemidocoptes mutans, fleas - Ceratophyllus gallinae, and some ticks - Argas persicus) (Sharma et al. 1990; Bennett \& Cheng 2012). Another ectoparasite of great economic impact on the poultry farm is the beetle poultry litter, Alphitobius diaperinus, with a significant negative impact on performance and production of birds. Ascaridia galli is an important nematode parasite of poultry; heavy infection causes death of the chickens, whereas moderate to low infection interferes with growth and productivity (Sharma et al. 1990). The control of this nematode infection using anthelmintics through medicated feed or water has reduced losses in the poultry industry. Currently, formulations based on ivermectin (IVM) for the treatment of parasitic infections of birds are available on the market, but they have not yet been approved for use in avian species and, therefore, there are still no studies on the profile of tissue depletion of these molecules in chickens destined for human consumption.

It is well established that the efficacy of any anthelmintic drug depends not only on its affinity for specific parasite target sites but also on its ability to reach high and sustained drug concentrations where the parasites are located. IVM is one of the most useful anti-parasitic agents (Mestorino et al. 2003). It is a member of the macrocyclic lactone family known as avermectins (AVM) derived from Streptomyces avermitilis (Echeverría et al. 2002), endectocides of wide spectrum of activity at low doses rates with high potency and low mammalian toxicity (Galarini et al. 2013) widely used for treatment and prevention of internal and external parasites in food-producing animals (Mestorino et al. 2003). IVM is effective when administered orally, parenterally or topically, and absorption is rapid by any of these routes (Echeverría et al. 2002). This compound when administered in water - was effective in removing Ascaris galli, Heterakis gallinarum and Capillaria spp. in poultry (Schepkins et al. 1985; Sharma et al. 1990; Todisco et al. 2008; Khayatnouri et al. 2011). It is a very lipophilic molecule, so residues remain for long

CONTACT Nora Mestorino noram@fcv.unlp.edu.ar $\Theta$ Laboratory of Pharmacological and Toxicological Studies (LEFyT), Faculty of Veterinary Science, Universidad Nacional de La Plata, 60 and 118, La Plata 1900, Argentina

(c) 2017 Informa UK Limited, trading as Taylor \& Francis Group 
periods in the treated animal tissues, especially those with a high fat content (Baynes et al. 2000). Until recently, there were some oral formulations to control internal and external parasites in game birds and fighting cocks in some countries, but most are no longer available on the market. In addition, no IVM formulations for avian production were available. However, extra-label use of this drug has been reported (Bennett \& Cheng 2012).

Residue studies are of fundamental importance in public health. Consumer safety is based on a series of measures including MRLs and ADIs as the most important. MRLs have been established by Commission regulations 37/2010, 418/2014 and 1390/2014 (EU 2010, 2014a, 2014b) for some AVMs in specific animal tissues (bovine, ovine, caprine, equine, fish), but there are no established MRLs for edible tissues of chicken. The European Union set the MRLs for IVM in edible tissues of food-producing mammals as follows: $100 \mathrm{ng} \mathrm{g}^{-1}$ in liver and fat, and $30 \mathrm{ng} \mathrm{g}^{-1}$ in kidney and muscle. Extrapolation of MRLs to the relevant minor species has been considered.

The aim of this study was to determine restriction periods for broiler chickens fed with a balanced feed mixed with premix containing IVM for 21 days in order to establish acceptable residual levels for human consumption according to European Union regulations.

\section{Materials and methods}

\section{Reagents and chemicals}

Ivermectin (IVM) pure reference standard (97\% purity) was obtained from Sigma Chemical Co. (St. Louis, MO, USA). Acetonitrile and methanol solvent used during the extraction and drug assay were of HPLC grade and purchased from J. T. Baker (Phillipsburg, NJ, USA). The N-methylimidazole and trifluoroacetic anhydride used for the derivatisation reaction were from Sigma-Aldrich Chemical Co. (Milwaukee, WI, USA). Solid-phase extraction (SPE) columns (Strata, $\mathrm{C}_{18}, 100 \mathrm{mg}, 1 \mathrm{ml}$ ) and analytical column (Kinetex $\mathrm{C}_{18}$ ) were obtained from Phenomenex (Torrance, CA, USA).

\section{Study design treatment and administration}

It is a common practice in the poultry industry to dose chickens by adding IVM to the feed or in the water system. Sixty-one-day-old BB chicks were fed with a pre-start and initiator feed supplemented with IVM at $5 \mathrm{mg} \mathrm{kg}^{-1}$ for 21 days. This means that if in 21 days a chicken consumes $1 \mathrm{~kg}$ of feed during the same time it also consumes $5 \mathrm{mg}$ of IVM $(238 \mu \mathrm{g}$ day $^{-1}$ ). We were not able to measure feeding rates in this study. However, according to Cobb-Vantress (2010), chicks of $1,7,14$ and 21 days old eat approximately 13, 28, 68 and $111 \mathrm{~g} \mathrm{day}^{-1}$. Assuming this intake, chicks in this study would have approximately consumed 65, 140, 340 and $555 \mu \mathrm{g}$ of IVM, respectively. Considering the chicks' body weight: $185 \mathrm{~g}$ (1-7 days), $465 \mathrm{~g}$ (7-14 days) and $943 \mathrm{~g}$ (14-21 days), the estimate daily IVM dosage was between 757 and $588 \mu \mathrm{g} \mathrm{kg}^{-1}$.

The chickens treated with IVM were euthanised by cervical dislocation after desensitisation by passage of an electric current through the head in groups of six animals at $0,1,2,4,8,10,15,20$ and 28 days post-treatment. The last time corresponds to the sacrifice for commercials purposes. Six chickens used as control (free of IVM) were euthanised before the experiment. Immediately after slaughter, liver, skin/fat, muscle and kidney samples were collected. Each sample was properly conditioned, placed in plastic bags, heat sealed, labelled and stored at $-20^{\circ}$ C until assay.

The protocol followed the Guide for the Care and Use of Agricultural Animals in Agricultural Research and Teaching (Federation of Animal Science Societies - FASS) and was approved by the Experimental Ethics Committee of the Faculty of Veterinary Science, UNLP, Argentina.

\section{Ivermectin analysis}

All tissue samples were analysed by HPLC with automated SPE and fluorescence detection following an adapted version of the methodology previously described (Echeverría et al. 2002; Mestorino et al. 2003). Tissue samples (muscle, liver, kidney and skin plus fat) were thinly sliced and $2 \mathrm{~g}$ were homogenised in $1 \mathrm{ml}$ of acetonitrile (Ultra Turrax $\mathrm{T}_{25}$ basic, IKA, Works Inc., Lincoln, NE, USA). The homogenate was mixed for $20 \mathrm{~min}$, sonicated for $10 \mathrm{~min}$ (ultrasound bath) and centrifuged at $2000 \mathrm{~g}$ for $10 \mathrm{~min}$ at $4^{\circ} \mathrm{C}$. The clear supernatant was transferred to a new tube and the extraction procedure was repeated once. The total supernatant obtained was 
placed on the appropriate rack of Aspec XL automatic SPE apparatus (Gilson, Villiers-le-Bel, France). Automatic sample preparation was performed using SPE $\mathrm{C}_{18}$ cartridges (Strata $\mathrm{C}_{18}, 100 \mathrm{mg}, 1 \mathrm{ml}$, Phenomenex), which were conditioned with $2 \mathrm{ml}$ of methanol, and followed by $2 \mathrm{ml}$ of water HPLC quality. All samples were applied to cartridges, washed with $1 \mathrm{ml}$ of water followed by $1 \mathrm{ml}$ of methanol/water $(1: 3, \mathrm{v} / \mathrm{v})$, dried with air for $2 \mathrm{~min}$ and finally eluted with $3 \mathrm{ml}$ of methanol of HPLC grade. The eluted volume was evaporated at $60^{\circ} \mathrm{C}$ to dryness in a vacuum concentrator (AVC 2-25CD Christ, Osterode, Germany). A fluorescent derivative was obtained by dissolving the dry residue in $100 \mu \mathrm{l}$ of a mixture of $\mathrm{N}$-methylimidazole solution in acetonitrile $(1: 1, \mathrm{v} / \mathrm{v})$. To initiate the derivatisation, $150 \mu \mathrm{l}$ of a solution of trifluoroacetic anhydride in acetonitrile $(1: 2, \mathrm{v} / \mathrm{v})$ were added. After completion of the reaction $(<30 \mathrm{~s})$ and mixing, the solution was transferred to autosampler polypropylene vials and an aliquot of $100 \mu \mathrm{l}$ was injected into the chromatographic system. HPLC analyses were carried out within $4 \mathrm{~h}$ to avoid the degradation of the fluorescent derivatives.

\section{Standard curve}

Standards were prepared by adding $0.5,1,2.5,5,10$, 20 and $30 \mathrm{ng}$ of IVM to test tubes, evaporating to dryness at $60^{\circ} \mathrm{C}$, and dissolving and derivatising as described above. Linear regression analysis using a least-square fit was performed.

\section{Chromatographic conditions}

The chromatographic system consisted of an isocratic pump (Gilson Inc. 307), an automatic injector (Gilson Inc. 234), a FluoroMonitor IM III Detector (Sp Thermo Separation products) set at an excitation wavelength of $365 \mathrm{~nm}$ and an emission wavelength of $475 \mathrm{~nm}$, and Eppendorf CH-30 Column Heater (set at a $30^{\circ} \mathrm{C}$ ). The system is controlled through the Unipoint $^{\oplus}$ Gilson system. An $\mathrm{C}_{18}$ column (Kinetex, $2.6 \mu \mathrm{m}, 4.6 \mathrm{~mm} \times 100 \mathrm{~mm}$; Phenomenex) and was eluted with a mixture of acetic acid $2 \%$ in watermethanol-acetonitrile $(4: 32: 64)$ at a flow rate of $1.5 \mathrm{ml} \mathrm{min}{ }^{-1}$ at $30^{\circ} \mathrm{C}$. Identification of IVM in bird tissues was accomplished by comparison with the retention times of the reference standards.
The precision of the extraction procedure and chromatography technique were evaluated by processing as replicates in six different occasions aliquots of pooled different tissue samples containing known amounts of IVM.

\section{Method validation}

The method for the identification of IVM in tissue broilers was validated in terms of the analytical parameters of linearity, precision, accuracy, LOQ and LOD, and selectivity following the guideline for the validation of analytical methods used in residuedepletion studies from the International Cooperation on Harmonization of Technical Requirements for the Registration of Veterinary Medicinal Products (VICH 2015).

Linearity was determinate using seven concentrations of IVM standard $(0.5,1,2.5,5,10,20$ and 30 $\mathrm{ng} \mathrm{ml}^{-1}$ ) injected three times into the chromatography system.

Blank tissue samples were fortified with IVM ranging between 0.5 and $30 \mathrm{ng} \mathrm{g}^{-1}$. IVM concentrations were determined from peak areas and the use of calibration curves obtained by running tissue samples from chickens not treated with IVM (i.e., chicken control) that were spiked with known concentrations of IVM. For tissue specimens as determined using the linear least squares regression procedure, a linear relationship existed in the calibration curve of IVM over the range of $0.5-30 \mu \mathrm{g} \mathrm{g}^{-1}$ for muscle, liver, kidney and skin plus fat.

Precision and accuracy of the method were determined by the evaluation of replicates of IVM-free samples $(n=6)$ fortified with IVM at different concentrations $\left(0.5,5,20,30 \mathrm{ng} \mathrm{g}^{-1}\right)$. Precision was expressed as coefficient of variation (\% CV). Accuracy, defined as the closeness between the experimentally measured and the true value, was determined by the differences between observed and calculated concentration results, and expressed as the relative error (\% RE) (Chandran \& Singh 2007).

The LOQ was calculated as the lowest IVM concentration $(n=6)$ on the standard curve that could be quantitated with precision not exceeding $20 \%$ and accuracy within $20 \%$ of nominal. The LOD was estimated by the analysis of 10 aliquots of control tissue (free of IVM). The noise of the baseline was 
measured; the average and standard deviation were calculated; the LOD corresponded to three times the $\mathrm{SD}$ (sign/noise $\geq 3 / 1$ ).

Selectivity is the ability of the method to distinguish between the analyte being measured and other different substances that might be present in the sample being analysed. The selectivity of the method was determined by comparing the chromatograms of IVM-free tissue samples with those of each tissue fortified with IVM. The lack of interferences in the separation suggests a high specificity of the chromatographic method and good selectivity of the extraction procedure. Tissue concentrations were expressed as $\mathrm{ng} \mathrm{g}^{-1}$.

\section{Withdrawal time}

The withdrawal periods for edible tissues of chickens (muscle, liver, kidney and skin plus fat) were estimated by linear regression analysis of the log-transformed tissue concentrations and determined at the time when the upper one-sided $95 \%$ tolerance limit for the residue was below the MRL, with a confidence of 95\% (EMEA 2002). IVM concentrations as a function of time found in muscle, kidney, liver and skin/fat were plotted and analysed with the program WT version 1.4 in order to recommend a period of withdrawal time for this experimental formulation.

\section{Results}

No adverse response was observed after feeding with feed supplemented with IVM at $5 \mathrm{mg} \mathrm{kg}^{-1}$ during 21 days. This method performed accurately and reproducibly over a range of $0.5-30 \mathrm{ng} \mathrm{g}^{-1}$ for IVM. The linear regression equation obtained for the proposed HPLC method as calibration curve was $y=(1.6884 \mathrm{E}-5 \pm 0.0695) x+(0.2962 \pm 0.0867)$ $(r=0.9969 \pm 0.00076)$, where $y$ is the area ratio; and $x$ is the analyte concentration $\left(\mathrm{ng} \mathrm{ml}^{-1}\right)$. The chromatographic analysis time was short and IVM was presented in $2.04 \pm 0.4 \mathrm{~min}$, and no peaks were observed in the vicinity of IVM retention time, attesting the method's selectivity (Figure 1).

Precision and accuracy of the method were determined by evaluation of replicates of drug-free samples $(n=6)$ fortified with IVM at different

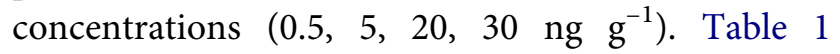
shows the validation parameters $\left(R^{2}\right.$, percentage recovery, precision (\% CV), accuracy (\% RE) and LOD) for different tissues spiked with $0.5,5,20$ and $30 \mathrm{ng} \mathrm{g}^{-1}$ of IVM. The mean global percentage of recoveries were $91.8 \%, 92.6 \%, 93.9 \%$ and $91.6 \%$ in liver, kidney, muscle and fat respectively, with CVs of $4.0 \%, 1.5 \%, 2.8 \%$ and $2.9 \%$ respectively. For individual levels and the overall evaluation of the working range, satisfactory results in the region of $70-120 \%$ were obtained. Within-laboratory precisions were $\leq 20 \%$ for the working range. The LOQ for each tissue assayed was $0.5 \mathrm{ng} \mathrm{g}^{-1}$, the lowest concentration of IVM residues evaluated with acceptable accuracy and precision, applying the complete analytical method here presented. The calculated LODs are presented in Table 1.

The validation method used here indicated that the analytical method used to extract, derivatise and quantify IVM in chicken tissues by chromatographic analysis using a fluorescence detector was appropriate.

\section{IVM tissue concentrations}

Table 2 shows the mean \pm SD tissue concentrations of IVM in muscle, kidney, liver and skin plus fat on different days after the end of treatment. The residue levels were low, with the highest concentration measured between the first and second days post-treatment in all tissues. The tissue with the highest concentration was liver, followed by skin/fat, kidney, and muscle. The higher concentrations were found in liver tissue, which is logical since IVM is a molecule that undergoes extensive hepatic metabolism, mainly by hydroxylation processes.

Considering that IVM was administered with food, concentrations found in different tested tissues were highly variable.

Linear regression analysis of the logarithmic transformed data can be considered for the calculation of the withdrawal periods. Using this approach, the withdrawal time is determined as the time when the onesided 95\% upper tolerance limit of the regression line with a 95\% confidence level is below the MRL. According to the residual concentrations found, optimal withdrawal times for edible tissues were 12 days for liver, 8 days for skin/fat and 10 days for kidney (Figure 2). In muscle tissue the concentrations found were always below the MRL established $\left(30 \mathrm{ng} \mathrm{g}^{-1}\right)$, that way the assay did not give any withdrawal time. 

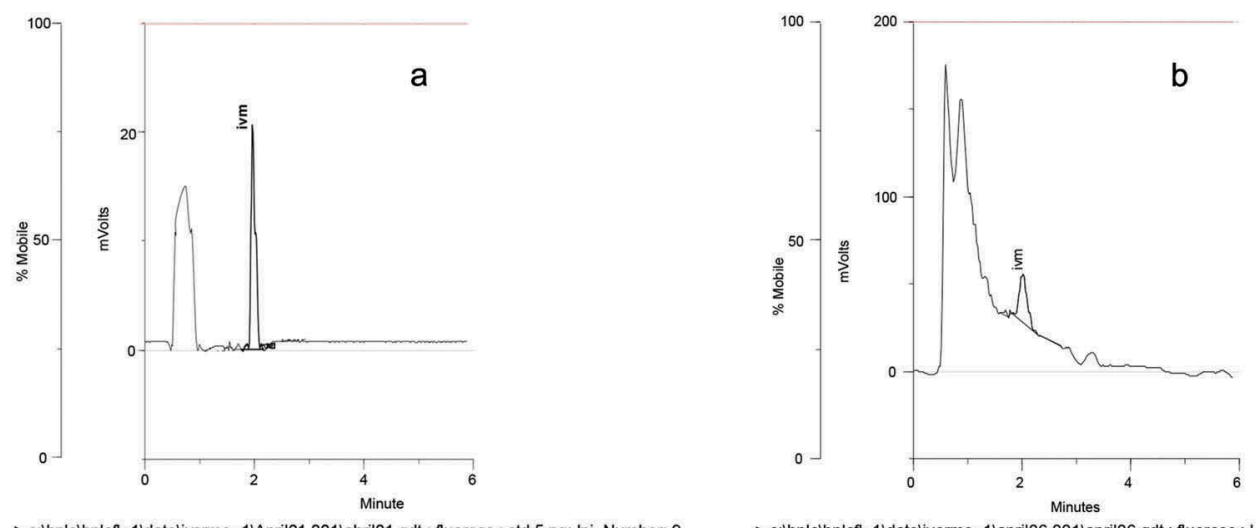

>c:Ihplc|hplcf $\sim 1$ ldateliverme 1Wpril01.001labril01.gdt : fluoresc : std $5 \mathrm{ng}:$ Inj. Number: 9

> c: :hplclhplcf 1)dateliverme 1lapril06.001 lapril06.gdt : fluoresc : Liv day0-A5: Inj. Number: 14
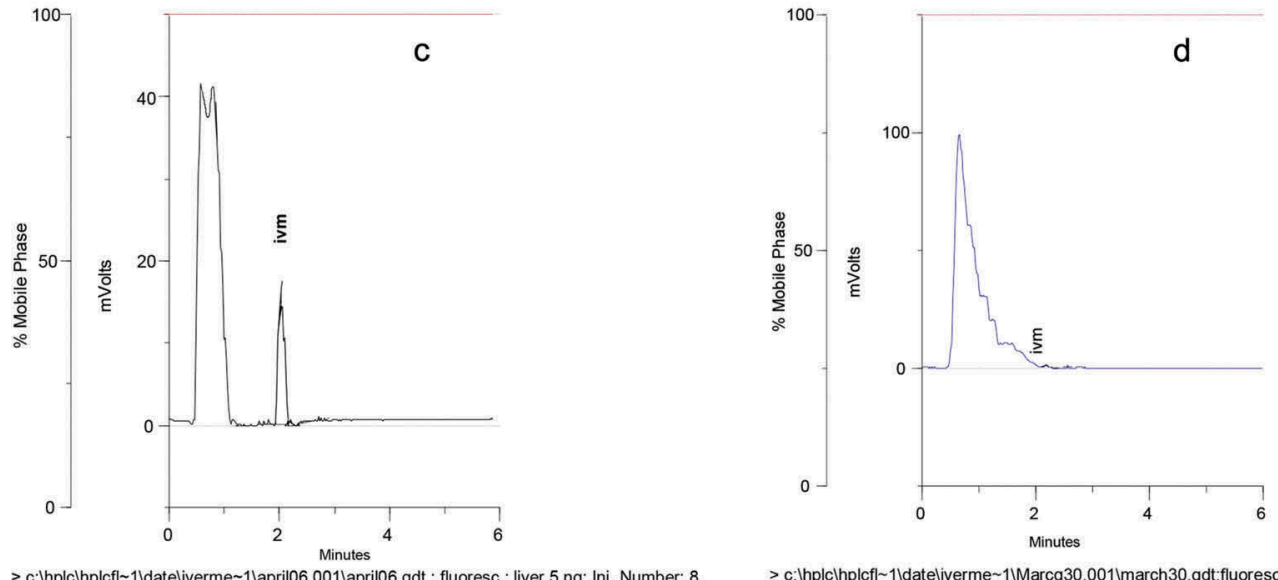

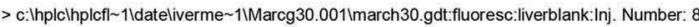

Figure 1. (colour online) Chromatograms of $5 \mathrm{ng} \mathrm{ml}^{-1}$ IVM standard (A), liver sample obtained at 0 day post-treatment to animal 5 (B), liver tissue fortified with $5 \mathrm{ng} \mathrm{g}^{-1}$ of IVM (C) and liver control (blank).

Table 1. Validation parameters for the determination of ivermectin residues in chicken tissues.

\begin{tabular}{|c|c|c|c|c|}
\hline \multirow[b]{2}{*}{ Parameter } & \multicolumn{4}{|c|}{ Chicken tissue } \\
\hline & Liver & Kidney & Muscle & Skin/fat \\
\hline$R^{2}$ & 0.9969 & 0.9985 & 0.9957 & 0.9970 \\
\hline \multicolumn{5}{|l|}{$0.5 n g g^{-1}(n=6)$} \\
\hline Recovery (\%) \pm SD & $95.6 \pm 5.1$ & $98.6 \pm 0.2$ & $101.1 \pm 3.0$ & $96.2 \pm 2.2$ \\
\hline Precision (\% CV) & 5.3 & 0.2 & 3.0 & 2.6 \\
\hline Accuracy (\% RE) $\pm S D$ & $-4.4 \pm 5.1$ & $-1.4 \pm 0.2$ & $1.1 \pm 3.0$ & $-3.8 \pm 2.2$ \\
\hline \multicolumn{5}{|l|}{$5.0 \mathrm{ng} \mathrm{g}^{-1}(n=6)$} \\
\hline Recovery (\%) \pm SD & $88.5 \pm 2.7$ & $92.4 \pm 3.1$ & $89.9 \pm 5.4$ & $94.3 \pm 3.6$ \\
\hline Precision (\% CV) & 3.0 & 3.4 & 6.0 & 3.9 \\
\hline Accuracy (\% RE) $\pm S D$ & $-11.5 \pm 2.7$ & $-7.6 \pm 3.1$ & $-10.0 \pm 5.4$ & $-5.7 \pm 3.6$ \\
\hline \multicolumn{5}{|l|}{$20 n g g^{-1}(n=6)$} \\
\hline Recovery $(\%) \pm S D$ & $87.5 \pm 2.6$ & $81.3 \pm 1.5$ & $85.2 \pm 0.6$ & $83.7 \pm 1.9$ \\
\hline Precision (\% CV) & 3.0 & 1.87 & 0.6 & 2.3 \\
\hline Accuracy (\% RE) $\pm S D$ & $-12.6 \pm 2.6$ & $-18.7 \pm 1.5$ & $-14.9 \pm 0.6$ & $-16.3 \pm 1.9$ \\
\hline \multicolumn{5}{|l|}{$30 n g g^{-1}(n=6)$} \\
\hline Recovery (\%) \pm SD & $95.5 \pm 4.6$ & $98.1 \pm 0.7$ & $99.5 \pm 1.4$ & $93.4 \pm 2.9$ \\
\hline Precision (\% CV) & 4.8 & 0.7 & 1.4 & 3.1 \\
\hline Accuracy (\% RE) $\pm S D$ & $-4.5 \pm 4.6$ & $-1.9 \pm 0.7$ & $-0.5 \pm 1.4$ & $-6.6 \pm 2.9$ \\
\hline \multicolumn{5}{|c|}{ Overall evaluation over the working range } \\
\hline Recovery $(\%) \pm S D(n=24)$ & $91.8 \pm 4.4$ & $92.6 \pm 8.1$ & $93.9 \pm 7.6$ & $91.6 \pm 5.6$ \\
\hline Precision (\% CV) & 4.0 & 1.5 & 2.8 & 2.9 \\
\hline Accuracy (\% RE) $\pm S D$ & $-7.0 \pm 3.3$ & $-5.1 \pm 4.0$ & $-2.6 \pm 5.0$ & $-5.0 \pm 1.4$ \\
\hline LOD $\left(n g g^{-1}\right)$ & 0.11 & 0.07 & 0.05 & 0.09 \\
\hline
\end{tabular}


Table 2. Mean \pm SD of ivermectin ( $\mathrm{ng} \mathrm{g}^{-1}$ ) concentrations measured in the depletion study in chickens after oral administration of IVM during 21 days with the food.

\begin{tabular}{lcccc}
\hline $\begin{array}{l}\text { Days post- } \\
\text { treatment }\end{array}$ & Kidney \pm SD & Liver \pm SD & Skin/fat \pm SD & Muscle \pm SD \\
\hline 0 & $9.57 \pm 3.58$ & $38.32 \pm 13.33$ & $7.91 \pm 3.73$ & $8.63 \pm 3.18$ \\
1 & $18.92 \pm 5.88$ & $73.54 \pm 36.40$ & $5.86 \pm 3.12$ & $4.49 \pm 2.52$ \\
2 & $6.55 \pm 2.93$ & $124.10 \pm 65.54$ & $49.41 \pm 29.72$ & $2.55 \pm 2.68$ \\
4 & $5.89 \pm 3.79$ & $3.76 \pm 3.03$ & $14.06 \pm 11.76$ & $2.94 \pm 2.61$ \\
8 & $2.28 \pm 1.87$ & $52.88 \pm 26.11$ & $32.37 \pm 15.01$ & $2.29 \pm 0.47$ \\
10 & $7.38 \pm 3.67$ & $18.19 \pm 13.95$ & $26.71 \pm 10.17$ & $1.53 \pm 1.09$ \\
15 & $7.14 \pm 3.86$ & $1.12 \pm 0.19$ & $3.11 \pm 1.88$ & $1.21 \pm 0.34$ \\
21 & $7.06 \pm 2.62$ & $3.81 \pm 2.65$ & $2.19 \pm 1.38$ & $0.93 \pm 0.34$ \\
28 & $4.70 \pm 1.90$ & $1.07 \pm 0.05$ & $2.01 \pm 1.05$ & $0.88 \pm 0.30$ \\
\hline
\end{tabular}
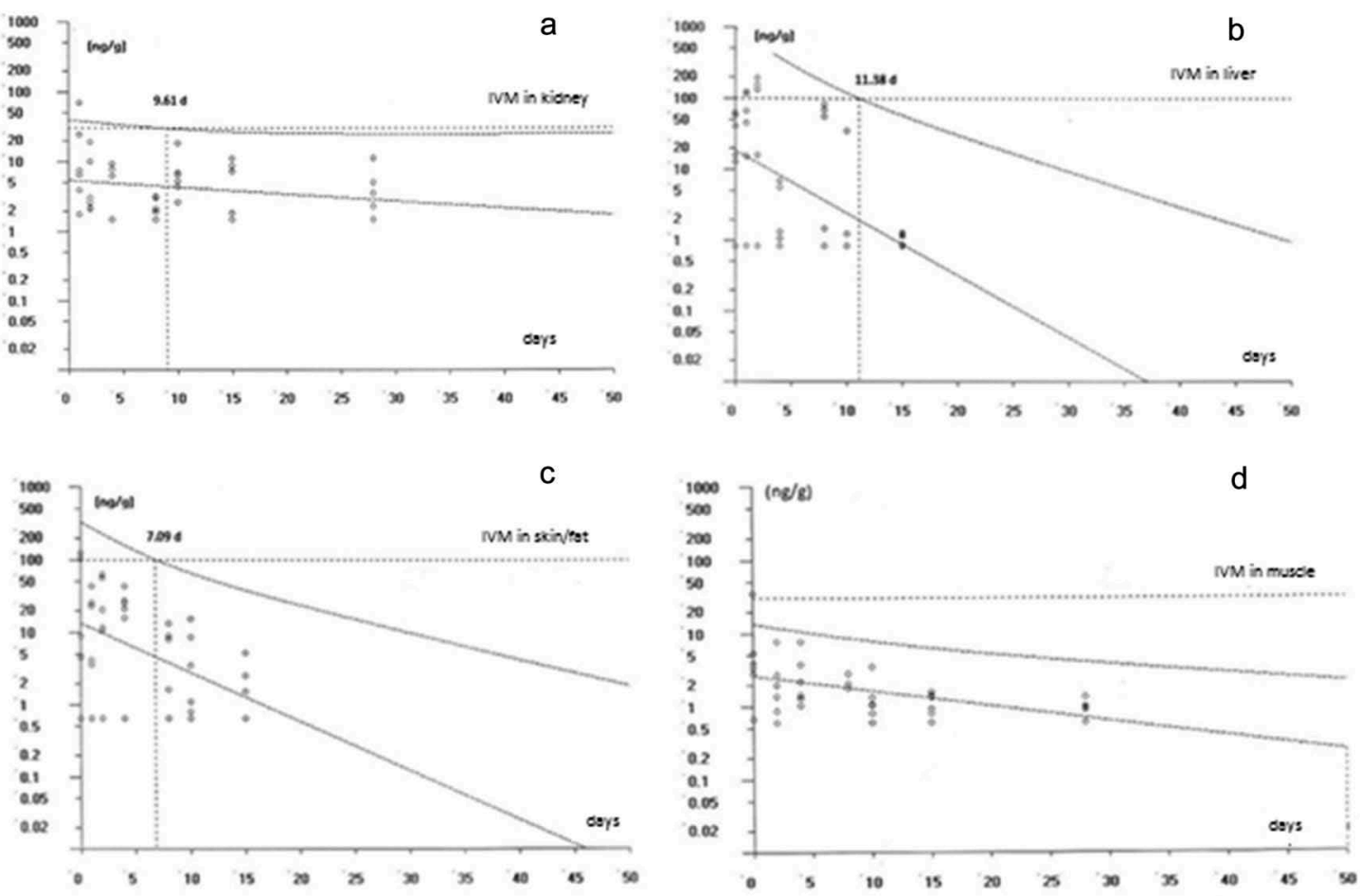

Figure 2. Withdrawal times of IVM calculated by linear regression analysis for kidney (a), liver (b), skin/fat (c) and muscle (d) (logarithmic transformed data).

\section{Discussion and conclusions}

Regarding the analytical methodology, for the working range evaluated, recovery and precision are according to the performance criteria for considering a quantitative method suitable for the determination of veterinary drug residues in foods when the concentration is between 1 and $100 \mu \mathrm{g} \mathrm{g}$ ${ }^{1}$ (FAO \& OMS 2009).

IVM is used in different animals (cattle, sheep, goats, pigs, horses) at dose rates of $100-500 \mu \mathrm{g} \mathrm{kg}^{-1}$ by subcutaneous, topical or oral routes, as a single-dose treatment only. Furthermore, it has also been studied in other animal species such as wild ruminants (reindeer, deer, camels and American bison) for which IVM extra-label use has been reported (Gonzalez-Canga et al. 2012; Moreno et al. 2015).

In poultry, anti-parasitic compounds are used extensively for disease prevention and treatment. Sharma et al. (1990) evaluated the IVM efficacy against Ascaridia galli infection in chickens at a dose of $300 \mu \mathrm{g} \mathrm{kg}^{-1}$ subcutaneously, finding an efficacy between $90 \%$ and $95 \%$ against immature and adult worms. Moreover, they found that the treated birds also had a better growth rate than the untreated control chickens.

In addition to controlling parasites effectively, some authors found an immunostimulatory effect 
in broilers at a high-rate dose of IVM $\left(5 \mathrm{mg} \mathrm{kg}^{-1}\right)$ (López-Olvera et al. 2006; Omer et al. 2012). Omer et al. (2012) treated 20-day-old chickens with IVM at dosage rates of $0.15,0.3,1,3$ and $5 \mathrm{mg} \mathrm{kg}^{-1}$ body weight. In another study carried out by Khayatnouri et al. (2011), the effect of IVM pour-on administration against Heterakis gallinarum infestation was evaluated at a dose of $500 \mu \mathrm{g} \mathrm{kg}^{-1}$. They obtained a reduction in egg count exceeding 98\%, concluding that IVM can be used in antiparasitic programmes in poultry.

However, the available information reporting tissue residue profiles after IVM treatment is scarce in poultry compared with other species (Goetting et al. 2011; Moreno et al. 2015). Edible tissues containing veterinary drug residues can pose risks to human health, including direct toxic effects, allergic reactions and increased parasites resistance (Ōmura \& Crump 2014).

Macrolide endectocides, such as IVM, are lipophilic compounds, so high concentrations will be found in edible tissues, particularly in those with a high fat content, where they can persist for prolonged periods (Canga et al. 2009). IVM is not highly metabolised and excretion is primarily via the faeces (Canga et al. 2009).

When IVM is administered to laying hens, residues are preferentially deposited in the egg yolk (Keukens et al. 2000; Moreno et al. 2015) and can be found in eggs laid for several days following cessation of treatment. Moreno et al. (2015) treated laying hens with IVM administered daily in water at $400 \mu \mathrm{g} \mathrm{kg}^{-1}$ dose for a 5-day period. They quantified IVM residues for a longer time in skin/fat until 15 days post-treatment, in the case of muscle and liver until 7 days after the end of treatment, and IVM kidney residues were measured only 3 days post-treatment. In contrast, Bennett and Cheng (2012) treated adult pigeons brooding squab with IVM in drinking water $\left(3.3 \mu \mathrm{g} \mathrm{ml}^{-1}\right)$ for 3 days and found high IVM residue concentrations in both liver $\left(58.5 \mathrm{ng} \mathrm{g}^{-1}\right)$ and breast muscle $\left(43.1 \mathrm{ng} \mathrm{g}^{-1}\right)$ at the end of treatment. In the present study, we found measurable concentrations below the MRL in all tissues until 28 days post-treatment. These differences can be explained by the vehicle used to solubilise the IVM. Moreno et al. (2015) and Bennett and Cheng (2012) used drinking water and we used initiator chickens' feed. The main drinking water medication disadvantages are related to the several factors that influence individual animal water intake, including biological (body weight, age), environmental (lighting period, environmental temperature) and management factors (composition of the diet).

Our results do not match those of Miller (1990) who administrated IVM to chickens with a diet of $2 \mu \mathrm{g} \mathrm{g}^{-1}$ of food for 5 weeks and found no residues of IVM in their livers, so this author did not establish a withdrawal period. The study performed by Miller was mainly about IVM efficacy against Alphitobius diaperinus, not about tissue profile depletion of IVM, where the experimental animals were sacrificed at the end of the treatment ( 5 weeks), therefore IVM residual levels in the liver were determined only at that sampling time.

In the European Union, MRLs of 100 (fat and liver) and $30 \mathrm{ng} \mathrm{g}^{-1}$ (for kidney and muscle) are established for IVM in all mammalian food-producing species. Withdrawal periods of 35, 28 and 18 days are recommended after IVM administration by the subcutaneous route in cattle, sheep and pigs, respectively. In some Latin American countries there are some IVM commercial formulations for use in the poultry industry. They are usually administered in water or food for 2, 3, 5 or 21 days. Withdrawal times are recommended in some of these formulations ( 2 or 7 days for meat and 0 days for eggs). According to European Union regulations, chickens fed for 21 days with this type of supplement containing IVM $\left(5 \mathrm{mg} \mathrm{kg}^{-1}\right)$ would be suitable for human consumption at 12 days post-treatment, i.e., at 33 days of life in this case. Considering that broiler chickens aged 45-54 days old are destined for the market, it can be stated that with the dosage scheme proposed in our study the chickens would be suitable for human consumption. These results would suggest that the IVM withdrawal period for growing chickens could be shorter than that of mammals, but pharmacokinetic studies need to be performed to test this hypothesis.

\section{Acknowledgements}

The authors thank Professor Pedro Zeinsteger for assistance with the manuscript.

\section{Disclosure statement}

No potential conflict of interest was reported by the authors. 


\section{References}

Baynes RE, Payne M, Martin-Jimenez T, Abdullah AR, Anderson KL, Webb AI, Craigmill A, Riviere JE. 2000. Extralabel use of Ivermectin and moxidectin in food animals. J Am Vet Med Assoc. 217:668-671.

Bennett DC, Cheng KM. 2012. Ivermectin residues in squab. Poult Sci. 91:2808-2811.

Canga AG, Prieto AMS, Liebana MJD, Martínez NF, Vega MS, Vieitez JJG. 2009. The pharmacokinetics and metabolism of ivermectin in domestic animal species. Vet J. 179:25-37.

Chandran S, Singh RSP. 2007. Comparison of various international guidelines for analytical method validation. Pharmazie. 62:4-14.

Cobb-Vantress. 2010. COBB Broiler management guide, s.l.: COBB-VANTRESS. Available from: http://www.cobb van tress.com/docs/default-source/cobb-500-guides/Cobb500_ Broiler_Performance_And_Nutrition_Supplement.pdf

Echeverría J, Mestorino N, Errecalde J. 2002. Comparative pharmacokinetics of ivermectin after its subcutaneous administration in healthy sheep and sheep infected with mange. J Vet Pharmacol Ther. 25:159-160.

[EMEA] The European Agency for the Evaluation of Medicinal Products. Veterinary Medicines and Inspection. 2002. Updated application software relating to note for guidance on approach towards harmonisation of withdrawal periods for meat. London: EMEA/CVMP/563/02.

EU. 2010. Commission Regulation (EU) 37/2010/CE of 22 December 2009 on pharmacologically active substances and their classification regarding maximum residue limits in foodstuffs of animal origin. Official Journal of the European Union, 20.1.2010, L 15/1. Available from: http://ec.europa.eu/health//sites/health/files/files/eudralex/ vol-5/reg_2010_37/reg_2010_37_en.pdf

EU. 2014a. Commission Implementing Regulation (EU) No 418/ 2014 of 24 April 2014 amending the Annex to Regulation (EU) No 37/2010 on pharmacologically active substances and their classification regarding maximum residue limits in foodstuffs of animal origin, as regards the substance "Ivermectin". Available from: http://eur-lex.europa.eu/legal-content/EN/ TXT/PDF/?uri=CELEX:32014R0418\&from=EN

EU. 2014b. Commission Implementing Regulation (EU) No 1390/2014 of 19 December 2014 amending the Annex to Regulation (EU) No 37/2010, as regards the substance "Eprinomectin". Available from: http://eur-lex.europa.eu/ legal-content/EN/TXT/PDF/? uri=CELEX:32014R1 390\&from $=\mathrm{EN}$

[FAO \& OMS] Food and Agriculture Organization of the United Nations \& World Health Organization. 2009. Guidelines for the design and implementation of national regulatory food safety assurance programmes associated with the use of veterinary drugs in food producing animals CAC/GL 71-2009. In: Animal food production, 2nd ed. Rome: p. 156-191. 9.

Galarini R, Saluti G, Moretti S, Giusepponi D, Dusi G. 2013. Determination of macrocyclic lactones in food and feed. Food Addit Contam: Part. 30:1068-1107.
Goetting V, Lee KA, Tell LA. 2011. Pharmacokinetics of veterinary drugs in laying hens and residues in eggs: a review of the literature. J Vet Pharmacol Ther. 34:521-556.

Gonzalez-Canga A, Belmar-Liberato R, Escribano M. 2012. Extra-label use of ivermectin in some minor ruminant species: pharmacokinetic aspects. Curr Pharm Biotechnol. 13:924-935.

Keukens HJ, Kan CA, van Rhijn JA, van Dijk J 2000. Ivermectin residues in eggs of laying hens and in muscle and liver of broilers after administration of feeds containing low levels of ivermectin. In: van Ginkel LA, Ruiter A, editors. Proceeding of the EuroResidue IV Conference, 810 May, 678-682. Veldhoven. The Netherlands.

Khayatnouri MH, Garedaghi Y, Arbati AR, Khalili H. 2011. The effect of ivermectin pour-on administration against natural Heterakis gallinarum infestation and its prevalence in native poultry. Am J Anim Vet Sci. 6:55-58.

López-Olvera JR, Höfle U, Vicente J, Fernández-De-Mera IG, Gortázar C. 2006. Effects of parasitic helminths and ivermectin treatment on clinical parameters in the European wild boar (Sus scrofa). Parasitol Res. 98:582-587.

Mestorino N, Turic E, Pesoa J, Echeverria J, Errecalde J. 2003. Pharmacokinetics in plasma of ivermectin after its oral (solution and tablets) administration to sheep. J Vet Pharmacol Ther. 26:307-309.

Miller RW. 1990. Use of ivermectin to control the lesser mealworm (Coleoptera tenebrionidae) in a simulated poultry broiler house. Poult Sci. 69:1281-1284.

Moreno L, Dominguez P, Farias C, Canton L, Virkel G, Maté L, Ceballos L, Lanusse C, Alvarez L. 2015. Ivermectin Pharmacokinetics, metabolism, and tissue/egg residue profiles in laying hens. J Agric Food Chem. 63:10327-10332.

Omer MO, Ashraf M, Javeed A, Maqbool A. 2012. Immunostimulatory effect of ivermectin on macrophage engulfment and delayed type hypersensitivity in broilers. J Anim Plant Sci. 22:250-255.

Ōmura S, Crump A. 2014. Ivermectin: panacea for resourcepoor communities? Trends Parasitol. 30:445-455.

Schepkins E, Duchatel VP, Vindevogel H. 1985. Traitement de l'ascaridiose et de la capillariose du pigeon par l'ivermectine. Ann Med Vet. 129:475-485.

Sharma RL, Bhat TK, Hemaprasanth. 1990. Anthelmintic activity of ivermectin against experimental Ascaridia galli infection in chickens. Vet Parasitol. 37:307-314.

Todisco G, Paoletti B, Giammarino A, Manera M, Sparagano O, Iorio R, Giannella B, Robbe D. 2008. Comparing therapeutic efficacy between ivermectin, selamectin, and moxidectin in canaries during natural infection with Dermanyssus gallinae. Animal biodiversity and emerging diseases. Ann N Y Acad Sci. 1149:365-367.

VICH. 2015. Studies to evaluate the metabolism and residue kinetics of veterinary drugs in food producing animals: validation of analytical methods used in residue depletion studies. VICH GL 49 (R) (MRK) January 2015. [cited 2016 Dec 1]. Available from: http://www.ema.europa.eu/docs/ en_GB/document_library/Scientific_guideline/2011/04/ WC500105053.pdf 